\title{
Doenças genéticas raras com abordagem qualitativa: revisão integrativa da literatura nacional e internacional
}

\author{
A qualitative approach to rare genetic diseases: an integrative \\ review of the national and international literature
}

Ítala Paris de Souza (https://orcid.org/0000-0002-9780-4974) ${ }^{1}$

Juliana Soares Androlage 'https://orcid.org/0000-0002-9993-5951) ${ }^{2}$

Roseney Bellato https://orcid.org/0000-0001-8266-7789) ${ }^{2}$

Reni Aparecida Barsaglini (https://orcid.org/0000-0002-8903-2695) ${ }^{1}$

${ }^{1}$ Instituto de Saúde Coletiva da Universidade Federal de Mato Grosso (UFMT). Av. Fernando Correa da Costa s/no, Boa Esperança. 78060900. Cuiabá MT Brasil. italaparis@hotmail.com. ${ }^{2}$ Faculdade de Enfermagem, UFMT. Mato Grosso MT Brasil.

\begin{abstract}
There are currently between six and eight thousand illnesses classified as rare diseases, $80 \%$ of which are of genetic origin and among the studies those of a quantitative and biomedical nature stand out. The objective of this study was to identify and describe the characteristics of scientific studies in Brazil and worldwide using a qualitative approach on rare genetic diseases published in indexed databases in the area of health and social sciences. The Scielo, Lilacs, Medline, PubMed, BDENF, Web of Science, Scopus and CINAHL databases were researched between 2013-2018 using the key words "Qualitative Research" and "Rare Disease." A total of 171 articles, classified by year, country, language, rare disease type, data collection strategy, knowledge area and theme were selected. The texts reveal the relevance of qualitative studies on rare genetic diseases in their ability to support organization, decision-making and health training in a way that responds to the social and individual needs of the community. It is important, however, to conduct further studies, especially within Brazil, that address rare genetic conditions, revealing the experiences and how they affect the personal, family, professional and organizational interactions in terms of the proper and effective modes of care.
\end{abstract}

Key words Rare disease, Genetics, Qualitative research, Experience of illness
Resumo Atualmente, há entre seis e oito mil adoecimentos catalogados por doenças raras, sendo que $80 \%$ são de origem genética e entre os estudos sobressaem os de natureza quantitativa e biomédica. Objetivou-se identificar e descrever as características dos estudos científicos, no Brasil e internacionalmente, com abordagem qualitativa, acerca das doenças genéticas raras publicados em bases indexadas na área da saúde e das ciências sociais. Utilizaram-se as bases de dados Scielo, Lilacs, Medline, PubMed, BDENF, Web of Science, Scopus e CINAHL, com os descritores: "Qualitative Research" e "Rare Disease", entre 2013-2018. Foram selecionados 171 artigos, classificados por ano, país, idioma, tipo de doença rara, estratégia de coleta de dados, área de conhecimento e tema. As produções revelam a pertinência dos estudos qualitativos sobre doença genética rara no seu potencial para subsidiar a organização, a tomada de decisões e a formação em saúde, de maneira que respondam às necessidades sociais e individuais da comunidade. É importante, todavia, desenvolver mais estudos, principalmente brasileiros, que abordem as condições genéticas raras, relevando as vivências e os afetamentos nas interações pessoais, familiares, profissionais e organizacionais perante os modos próprios e efetivos de cuidar.

Palavras-chave Doença rara, Genética, Pesquisa qualitativa, Experiência do adoecimento 


\section{Introdução}

O reconhecimento do que se designa por doenças genéticas raras como um problema de saúde global vem ganhando espaço de discussão, cada vez maior, no Brasil e no mundo. Elas afetam cerca de $8 \%$ da população mundial e, no Brasil, estima-se que 13 milhões de pessoas são acometidas $^{1}$. Calcula-se que existam entre 6 e 8 mil doenças raras no mundo e, para $95 \%$ delas, não há tratamento específico até o momento ${ }^{2}$.

Segundo a associação de pessoas com doenças raras na Europa ${ }^{3}$, doença rara, também conhecida pela denominação 'doença órfã', é qualquer doença que afeta pequena porcentagem da população e é caracterizada por ampla diversidade de sinais e sintomas que variam a depender da doença e de como a pessoa a experiencia. Parte significativa delas tem origem genética, representando cerca de $80 \%$ do total - e estas permanecem ao longo da vida, mesmo que os sintomas não apareçam imediatamente.

Há de se considerar que as doenças genéticas raras, visto serem complexas, podem se apresentar de forma degenerativa e cronicamente debilitantes, afetando as capacidades físicas, mentais, sensoriais e comportamentais da pessoa adoecida e sua família ${ }^{4}$. Tal perfil nos aponta que, a depender da especificidade de cada doença e do modo como incide na vida dessas pessoas, demandará cuidados complexos e contínuos ao longo do tempo.

Em termos de definição, ainda não há um consenso único sobre doenças raras, sendo que, geralmente, no âmbito dos sistemas de saúde, tem-se como base o critério da prevalência ou do número de pessoas por elas afetadas ${ }^{5}$. Na União Europeia, o termo "doença rara" inclui aquelas que afetam menos de $5 \mathrm{em}$ cada 10.000 pessoas, enquanto que nos EUA se refere a doenças que afetam menos de 200.000 pessoas no país ${ }^{1}$. No Brasil, são assim consideradas aquelas que afetam até 65 pessoas em cada 100.000 indivíduos, ou seja, 1,3 pessoa para cada $2.000^{2}$.

É de se destacar, dessa forma, a diversidade de definições; no entanto, autores sugerem que qualquer tentativa de harmonizar seus conceitos deve se concentrar em critérios objetivos padronizados, tais como limiares de prevalência, evitando nomeações qualitativas ${ }^{6}$.

Dado esse panorama geral, que mostra incertezas quanto às doenças raras, nosso interesse é conhecer o perfil dos estudos qualitativos sobre tal temática, pois entendemos que nos inúmeros estudos e publicações nas diferentes áreas do conhecimento têm predominado as questões clínicas, pautadas em aspectos específicos de determinada síndrome e/ou a dimensão quantitativa de acometimentos de certas condições raras. Ao mesmo tempo, parece-nos ser necessário conhecer como, em que medida e com quais enfoques têm sido desenvolvidos estudos de abordagem qualitativa.

A pesquisa qualitativa parte do pressuposto que existe uma relação dinâmica entre o mundo real e o sujeito, voltando seu olhar para o "estudo da história, das relações, das representações, das crenças, das percepções e das opiniões, produtos das interpretações que os humanos fazem a respeito de como vivem, constroem seus artefatos e a si mesmos, sentem e pensam"7.

Assim, buscamos focar nas publicações científicas embasadas no método qualitativo sobre doenças genéticas raras publicadas nos últimos cinco anos, coincidindo com o crescimento exponencial da produção científica brasileira e mundial sobre o tema ${ }^{8}$. E, apesar da grande expansão, a pesquisa qualitativa ainda se depara com desafios para sua consolidação, com poucas discussões oriundas das Ciências Humanas e Sociais na sua interface com a saúde9. Situação semelhante entendemos envolver as discussões acerca das doenças genéticas raras, que tiveram importante incremento como foco de pesquisas, mas que ainda carecem de estudos de cunho qualitativo.

Dessa forma, para oferecer maior visibilidade, as características dos estudos científicos que vêm sendo publicados acerca das doenças genéticas raras, optamos, como primeira aproximação, por realizar levantamento exploratório. Assim, foi objetivo do estudo identificar e descrever as características gerais, estratégia de coleta de dados e temas abordados em estudos científicos sobre doenças raras, com abordagem qualitativa, publicados em bases indexadas na área da saúde e das ciências sociais, nacionais e internacionais, ao longo dos anos 2013-2018.

\section{Metodologia}

Trata-se de uma revisão integrativa da literatura ${ }^{10}$ que explorou bases científicas da área da saúde e das ciências sociais por meio de levantamento da publicação científica qualitativa sobre doenças genéticas raras. A variada estrutura de amostragem das revisões integrativas ${ }^{10}$,em conjunto com a multiplicidade de propósitos, tem o potencial de resultar um retrato abrangente de conceitos 
complexos, teorias ou problemas de atenção à saúde de importância para os contexos sociais, conforme discorridos neste estudo.

O presente artigo é fruto da reunião dos principais achados da revisão bibliográfica feita conjuntamente por duas das coautoras e doutorandas, no processo de elaboração de suas respectivas teses sobre a experiência familiar de cuidado no bojo dos adoecimentos raros.

Para conduzir esta revisão de pesquisa, delineou-se os seguintes processos: identificação da questão de pesquisa; busca na literatura dos estudos; avaliação dos dados; análise; síntese dos dados; e apresentação ${ }^{10}$. Como ponto de partida, foi estabelecida uma pergunta norteadora a responder: "como se caracterizam, ao longo dos últimos cinco anos, as publicações científicas nacionais e internacionais sobre doenças genéticas raras, disponíveis nas bases consultadas, que empregaram o método qualitativo, no que tange aos locais de produção, às estratégias de coleta de dados, área de conhecimento e aos temas enfocados?”.

Norteados por essa indagação foi seguido rigoroso processo de captura, seleção e sistematização dos artigos cujos passos estão descritos, sequencialmente, a seguir: inicialmente, os artigos foram capturados no Portal Biblioteca Virtual em Saúde (BVS), eleito pela sua abrangência e pela reconhecida relevância para a divulgação do conhecimento produzido na área de saúde, abarcando as seguintes bases de dados: Scielo (Scientific Electronic Library Online); Lilacs (Literatura Latino-Americana e do Caribe em Ciências da Saúde); Medline (Literatura Internacional em Ciências da Saúde); PubMed (National Library of Medicine); BDENF (Bases de dados em Enfermagem). Além destas, lançamos mão de bases de acessos restritos, como a Web of Science, Scopus e CINAHL.

Não ignoramos, contudo, os importantes dados existentes em bancos de teses e dissertações, sites oficiais (como o da Orphanet, criado na França pelo Instituto Nacional Francês para a Saúde e Investigação Médica e o da Organização Mundial da Saúde), revisões/resenhas de livros e anais de eventos científicos que, embora passem por um crivo avaliativo diferente ao dos artigos científicos, merecem uma atenção específica.

Após simulações exploratórias de busca, os termos adotados foram Qualitative Research e Rare Disease. Optamos por empregá-los separados ou combinados - fazendo uso do operador booleano AND - para que fossem suficientemente sensíveis à captura das produções de abordagem qualitativa.
Nesse ponto, vale um destaque importante no que se refere à sensibilidade dos descritores escolhidos. Cientes de que os modos de nomear as doenças genéticas raras podem variar, a depender da área de estudo ou país de origem (encontramos variações como enfermidade rara, adoecimento raro, distúrbio raro), optou-se pela utilização dos termos em inglês por entendermos que as revistas científicas têm exigido, em sua maioria, que o artigo a ser publicado traga o resumo em inglês, assim como as palavras-chave ou descritores. Dessa maneira, nos casos em que o termo rare disease não fosse utilizado ao longo do texto, ainda poderíamos capturá-lo pelo termo presente no abstract e key word.

Como delimitador foi estabelecido o período de cinco anos, mais especificamente junho de 2013 a junho de 2018, verificando, assim, todos os textos disponíveis na íntegra, sem restrição de idioma. A primeira busca geral, realizada em junho de 2018, resultou em um total de 1.266 textos.

Todos os estudos identifcados por meio da estratégia de busca foram avaliados através da análise dos títulos e resumos visando filtrá-los em função do objetivo proposto. Nas situações em que os títulos e os resumos se mostraram insufcientes para definir a seleção inicial, procedeu-se à leitura na íntegra da publicação. Aplicou-se, assim, os seguintes critérios de exclusão: a) repetidas/duplicidade; b) estudos de caso clínico de determinada doença; c) que tratavam de doenças raras em animais/catástrofes/problemas raros na natureza; d) que abordavam complicações/desfechos raros decorrentes de procedimentos cirúrgicos; e) que discutiam complicações raras decorrentes de terapias medicamentosas específicas; f) que traziam a construção/avaliação de questionários/instrumentos validadores para identificação diagnóstica de doença rara específica; g) que apresentavam e discutiam metodologicamente tipos de estudos em pesquisas; h) que avaliavam a adesão de pessoas com adoecimento raro na testagem de medicações; i) guias/protocolos de práticas clínicas; $\mathrm{j}$ ) resenhas de livros/ book review. Após essa filtragem, chegamos ao total de 171 publicações que atendiam ao objetivo proposto, como ilustra a Figura 1.

Os artigos selecionados nessa segunda etapa advêm de plataformas bastante abrangentes e predominantemente biomédicas, como a PubMed e Lilacs, embora incluam textos oriundos das Ciências Sociais e Humanas e da pesquisa qualitativa em saúde, mesmo que em tímida quantidade. Já a Web of Science, Scopus e 


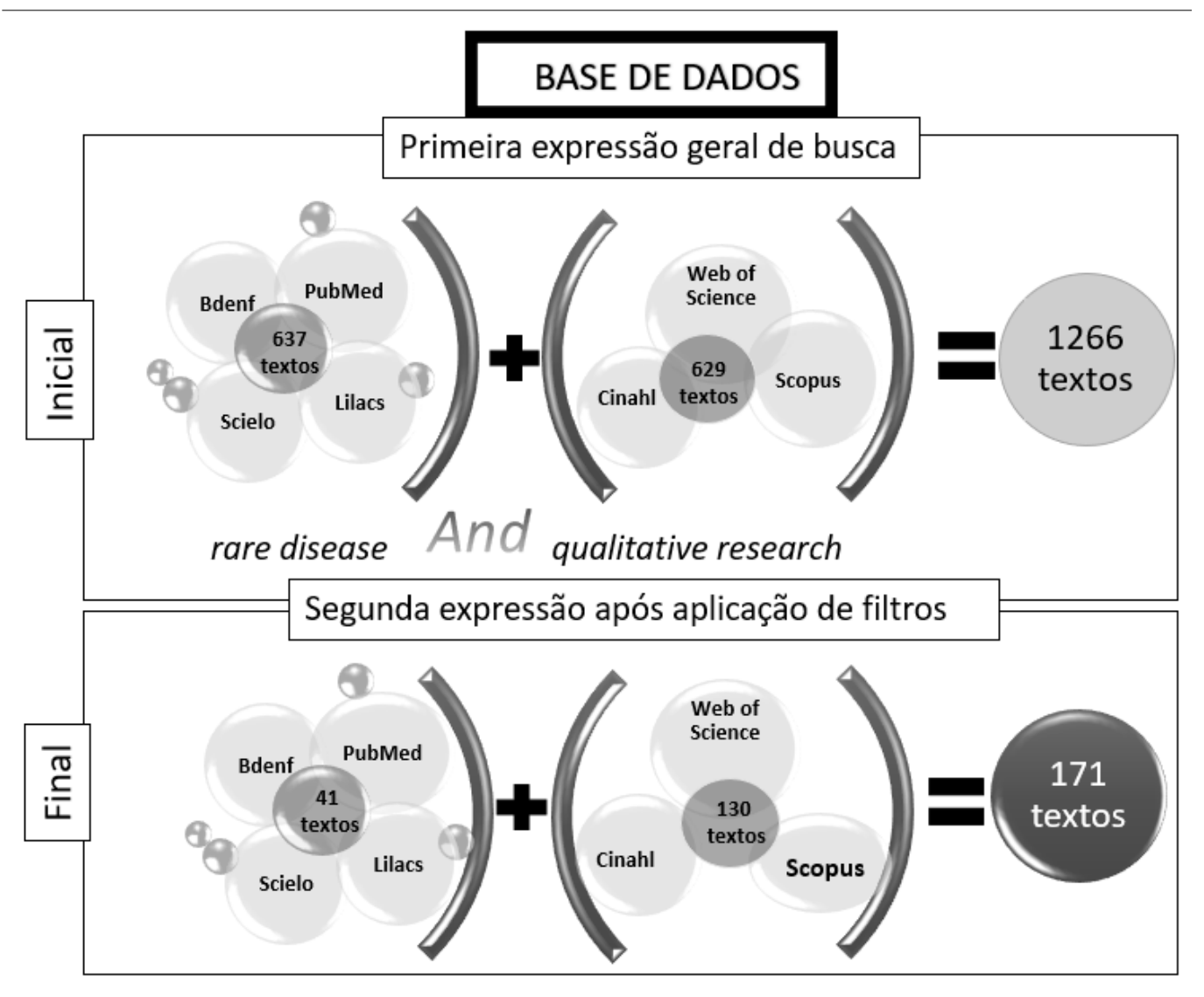

Figura 1. Número de produções encontradas inicialmente e resultado final conforme o tipo de base de dados (2019).

CINAHL cobrem a maioria dos campos científicos, porém seu acesso fechado, pertencente a provedores comerciais, limitam o compartilhamento das informações ${ }^{11}$.

A relação dos textos selecionados e analisados nesta revisão encontram-se no Quadro 1, para acesso dos que tenham interesse.

Diante destes 171 artigos selecionados, identificaram-se determinadas informações como título, ano de publicação, país de origem, área de concentração, objetivo, tipo de doença rara, estratégia de coleta de dados utilizada e principais temas abordados. O processo de captura das publicações e análise dos dados foi realizado por duas pesquisadoras, que desenvolveram esse trabalho de forma conjunta. Esses dados foram sistematizados, individualmente, em uma planilha do Microsoft Excel 2010 e da qual foi extraída par- te dos dados que foram organizados e apresentados em duas categorias de descrição e análise, respondendo aos objetivos do estudo.

A primeira categoria, mais descritiva, intitulada Características gerais das publicações, ocupase dos atributos/propriedades gerais dos textos selecionados, no que se refere a ano de publicação, filiação dos autores por área do conhecimento (considerando a área do autor principal), local de origem das produções (considerando o país onde foram realizadas as pesquisas), idioma e tipo de doença rara. A segunda categoria, intitulada Estratégia de coleta de dados e temas abordados nas publicações, apresenta o panorama geral acerca de como se deu a coleta de dados e os principais temas identificados no conjunto das produções selecionadas. 


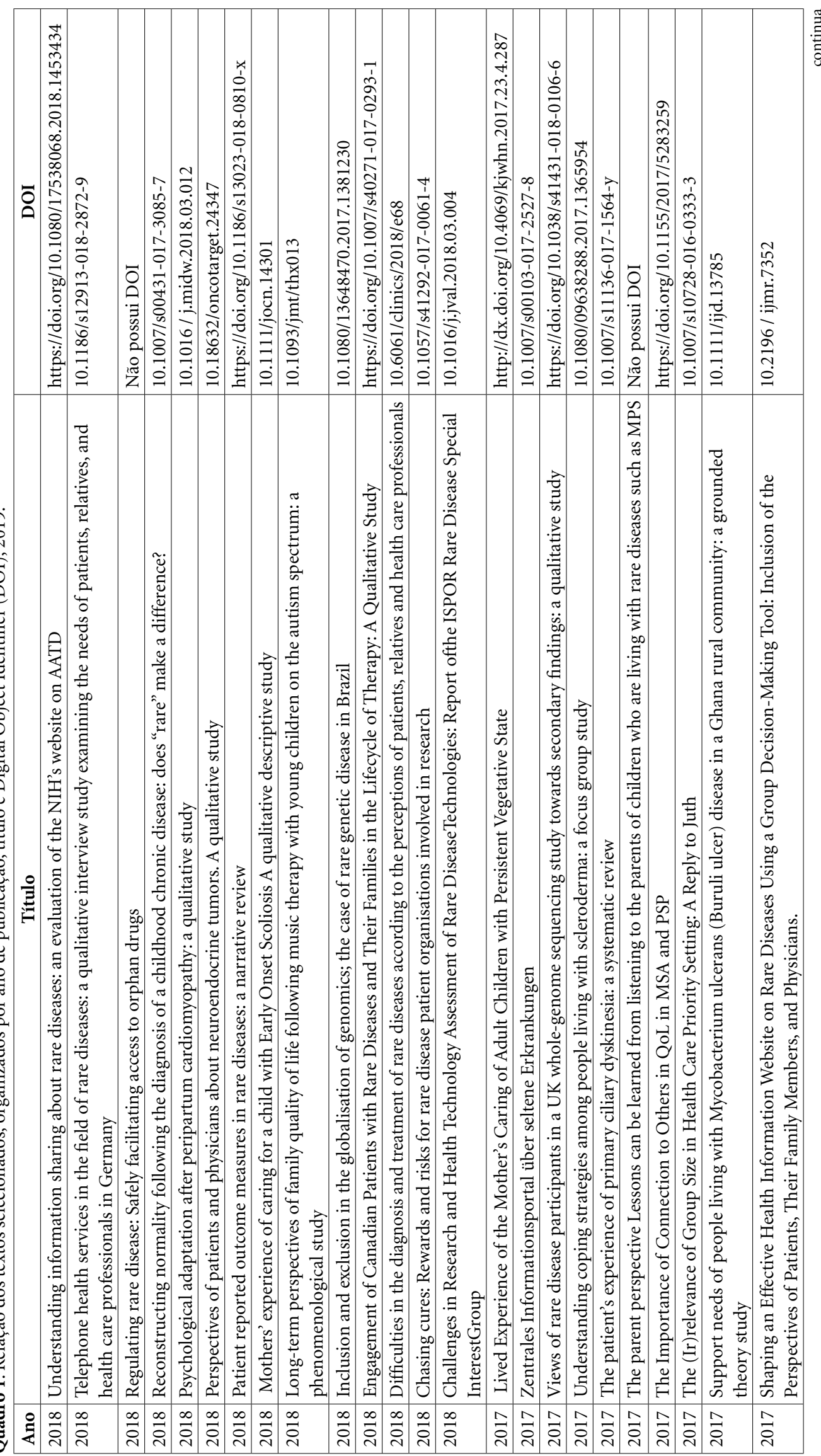




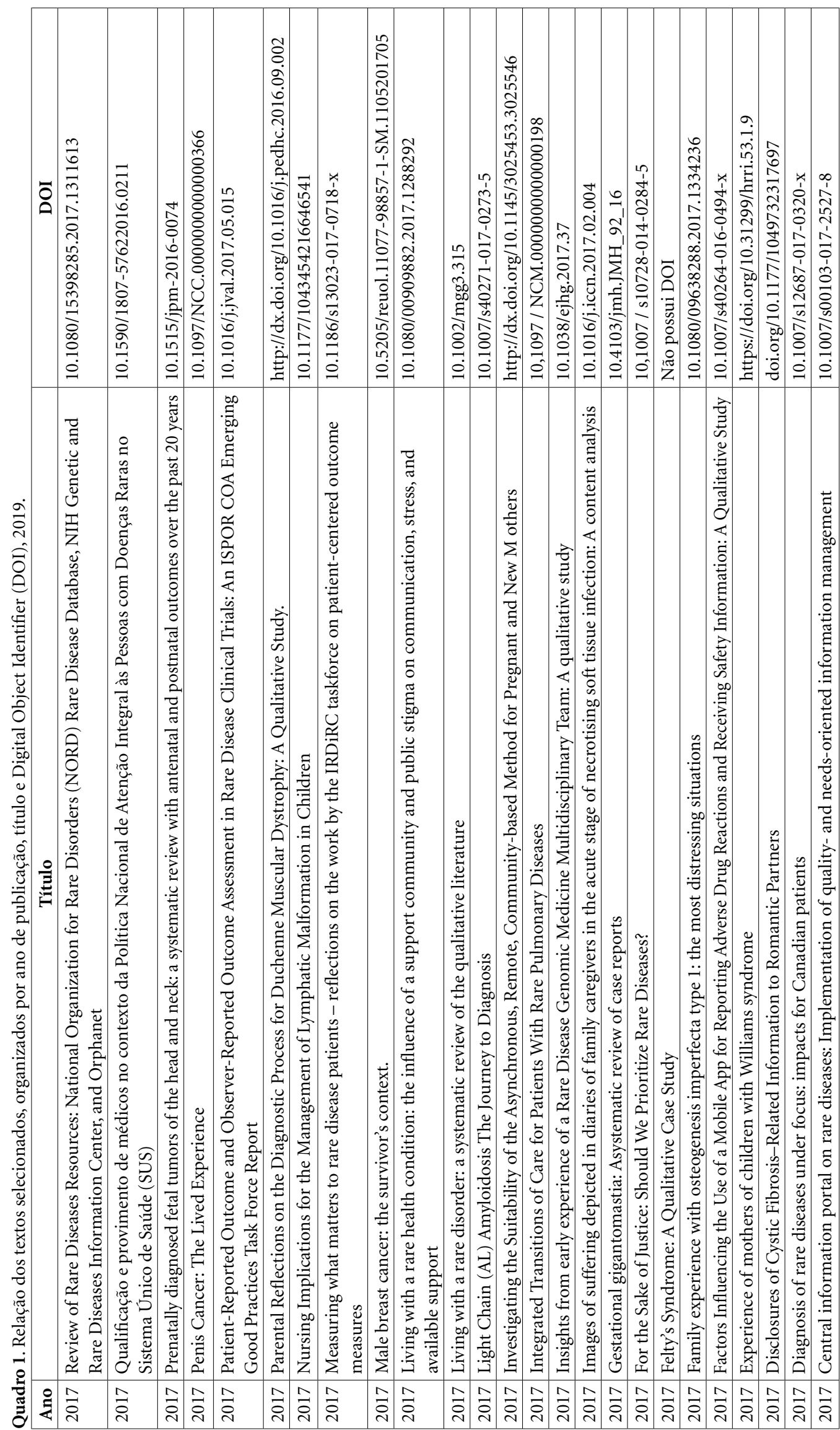




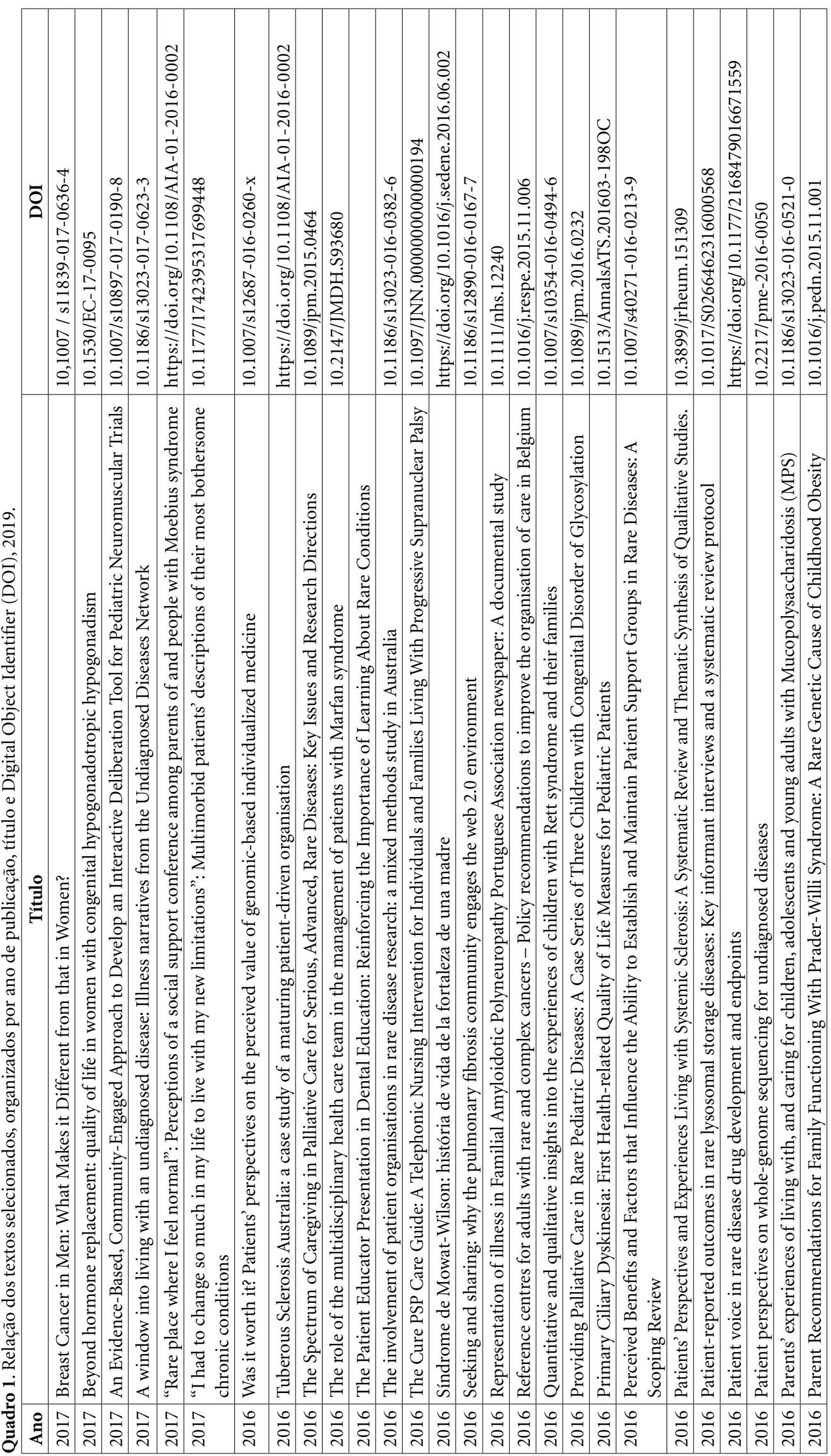




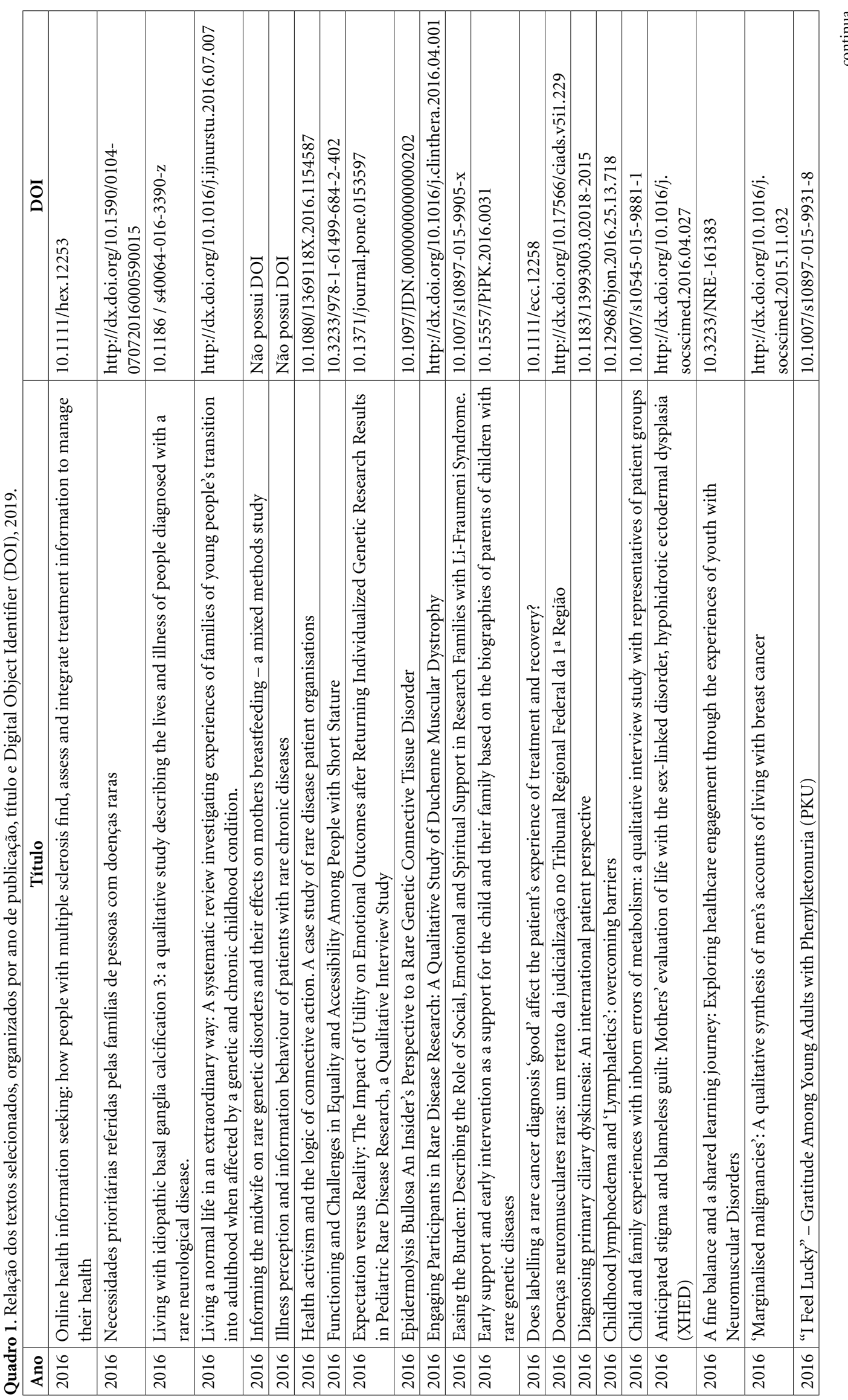




\begin{tabular}{|c|c|c|c|c|c|c|c|c|c|c|c|c|c|c|c|c|c|c|c|c|}
\hline & 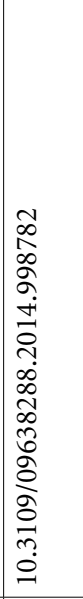 & 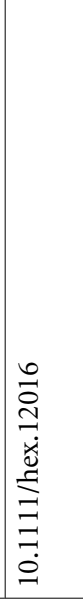 & 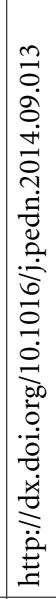 & 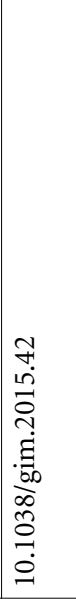 & 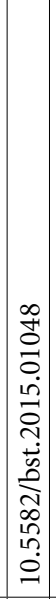 & 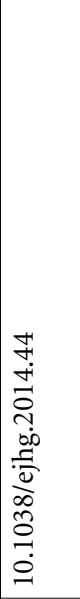 & 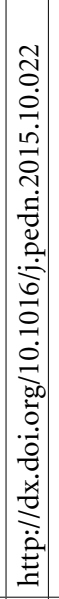 & 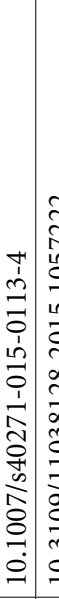 & 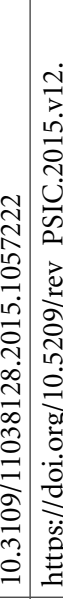 & 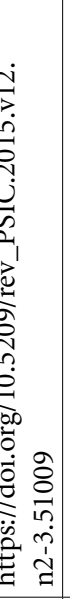 & 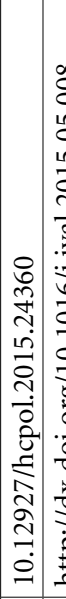 & 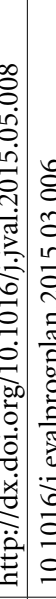 & 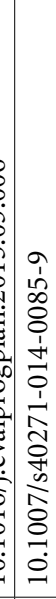 & 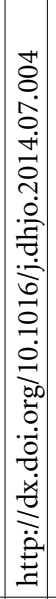 & 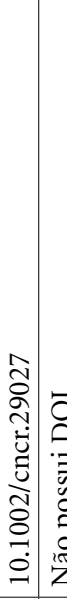 & 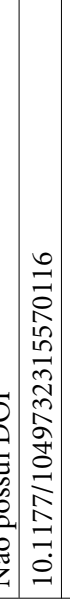 & 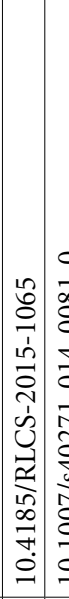 & 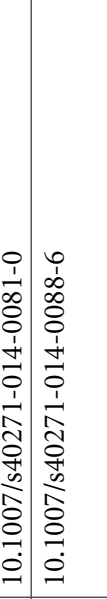 & 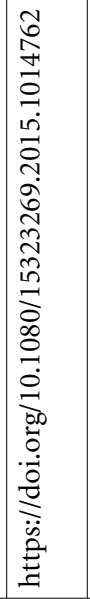 & \\
\hline & 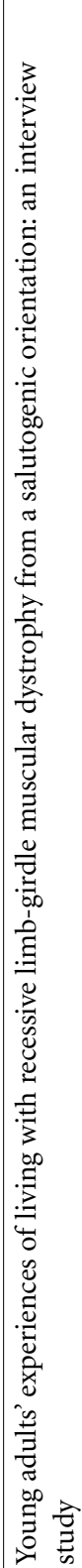 & 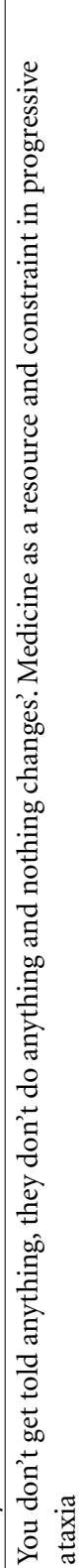 & 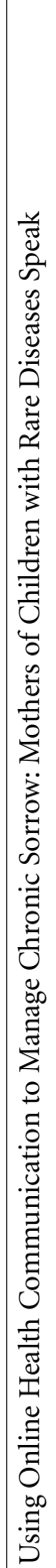 & 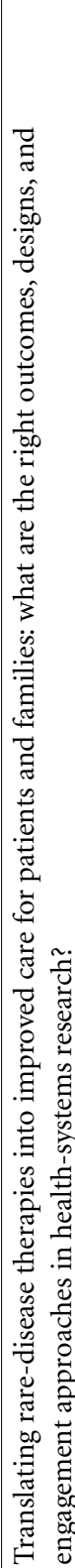 & 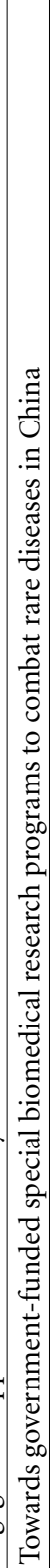 & 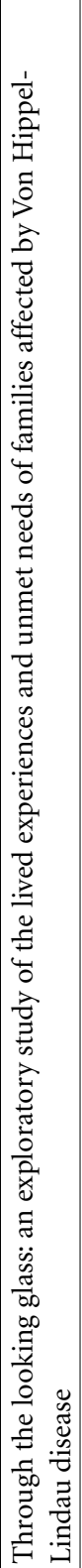 & 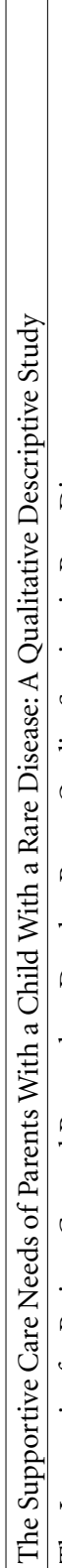 & 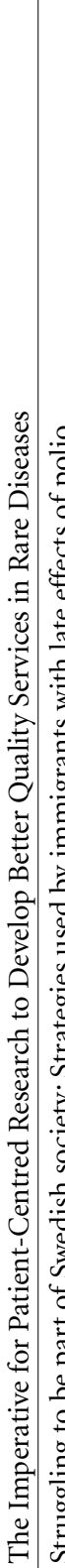 & 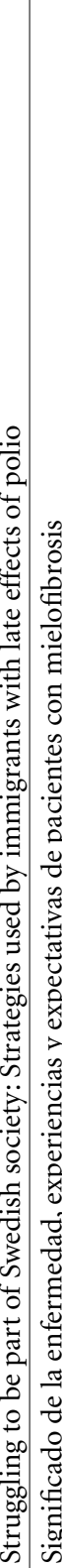 & 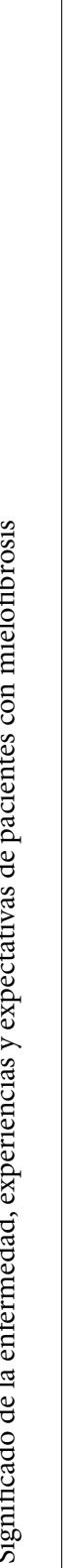 & 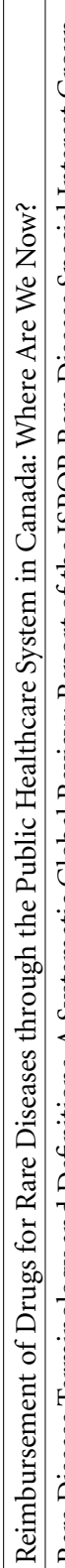 & : & 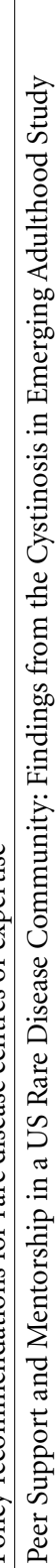 & 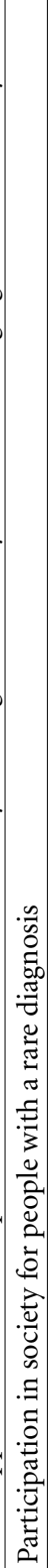 & 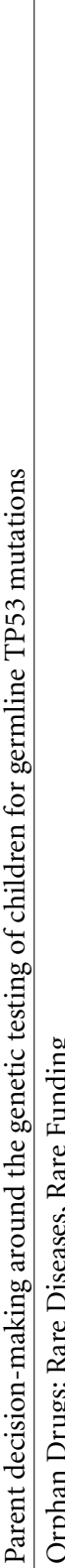 & 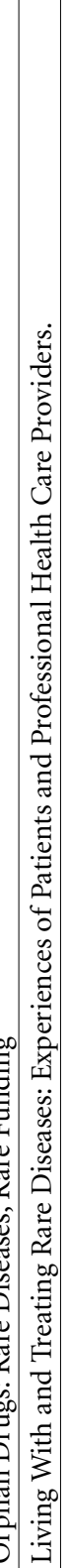 & 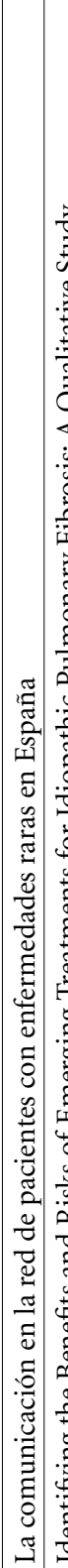 & 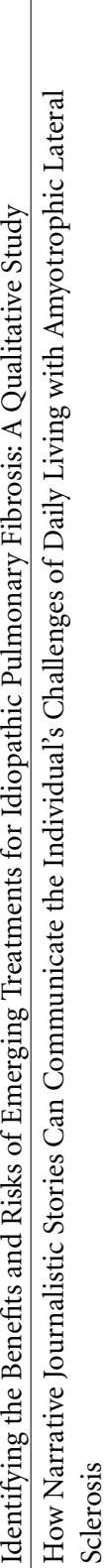 & 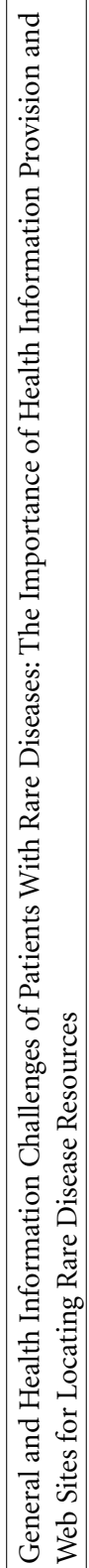 & \\
\hline & & & $\stackrel{n}{\stackrel{n}{n}}$ & & & & & & & & & & & & & & & & & \\
\hline
\end{tabular}




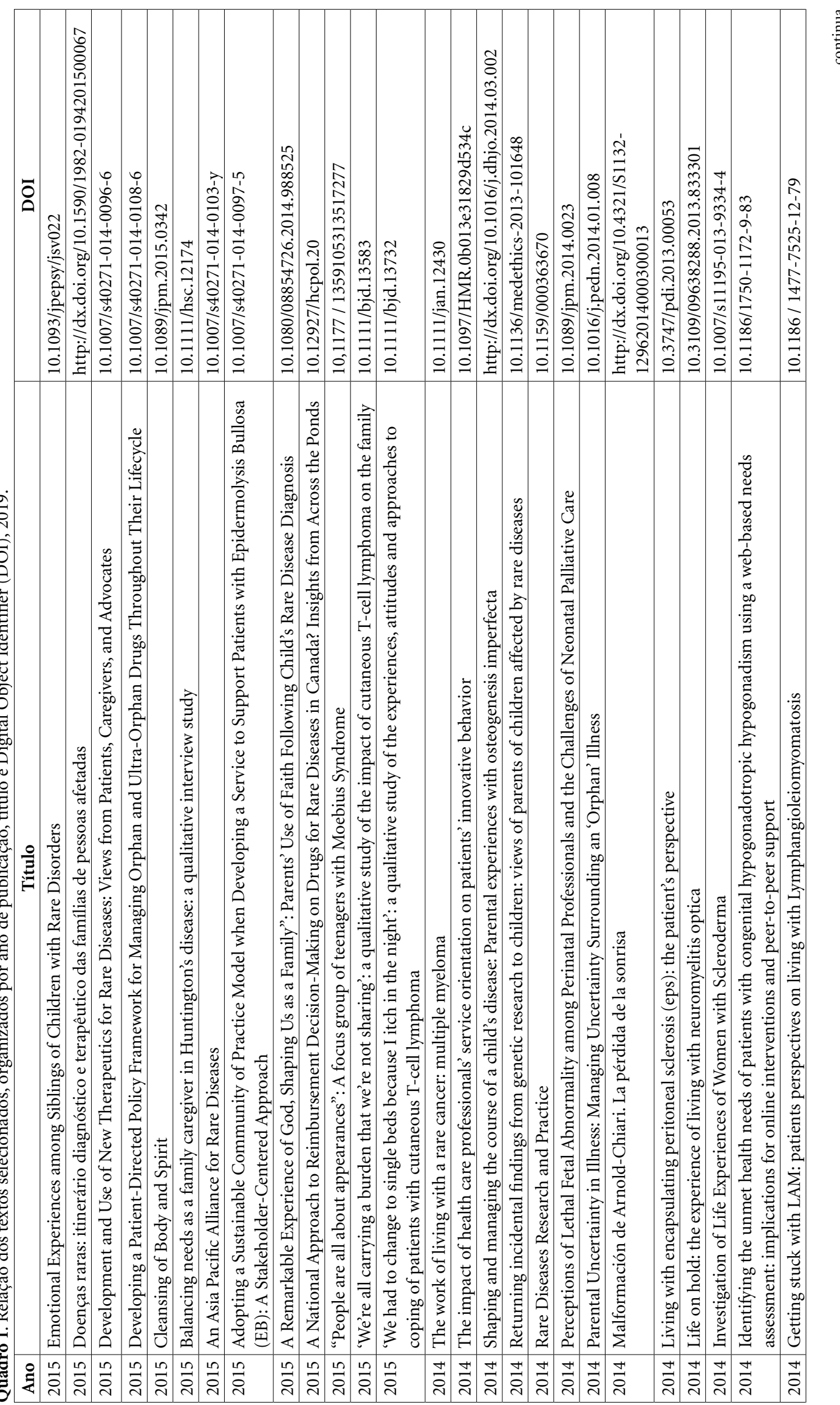




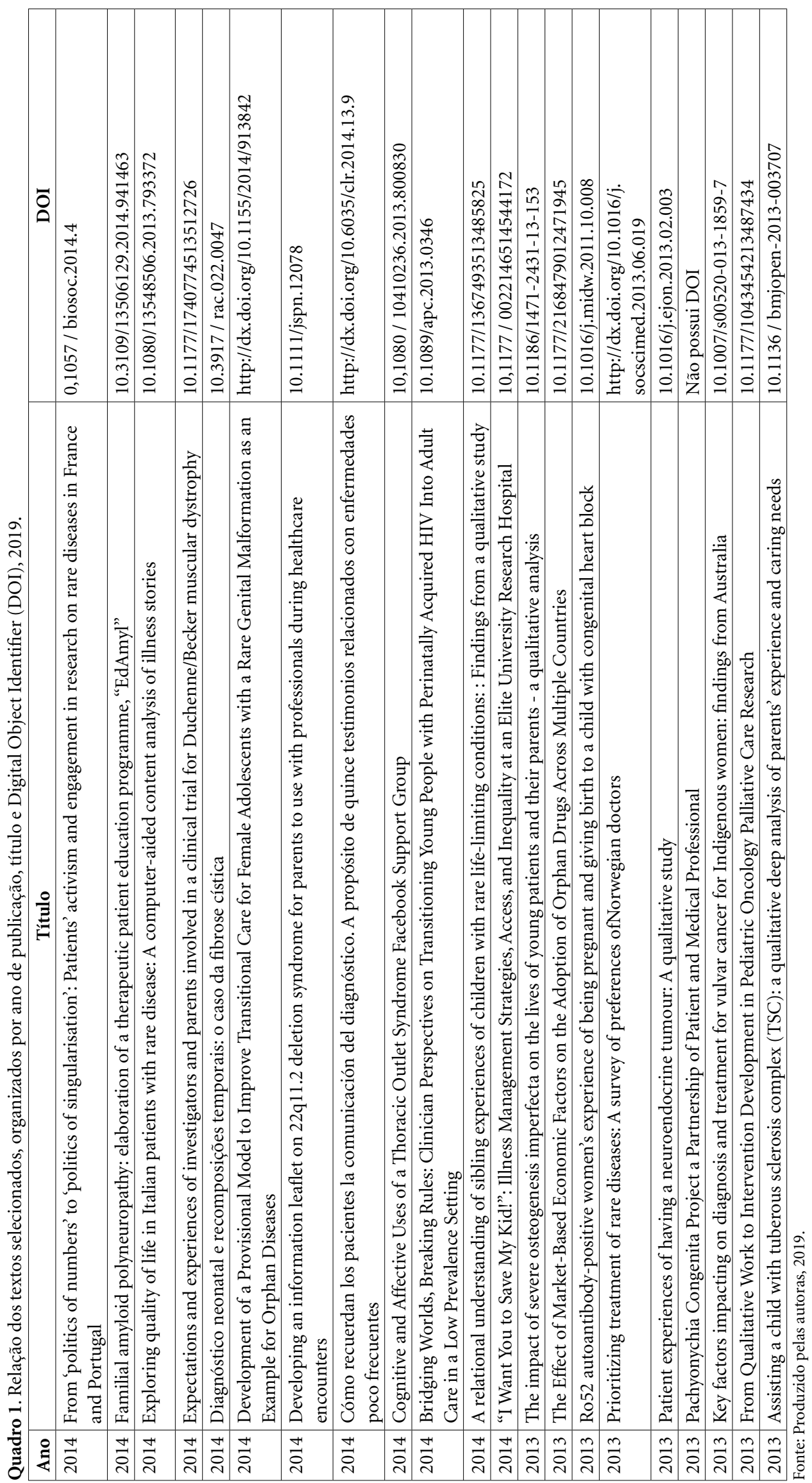




\section{Resultados e discussões}

\section{Características gerais das publicações}

Nas duas últimas décadas tem crescido o reconhecimento de que as doenças raras são um importante problema médico e social, imbricado substancialmente na consciência pública como resultado do trabalho de grupos de associações de pessoas e familiares que, em formato de redes, aglutinam contatos, vínculos e conexões que promovem as interações presenciais e virtuais, expandindo fronteiras identitárias e limites geográficos $^{12}$.

O presente estudo, abarcando interstício temporal 2013-2018, mostra que a distribuição das publicações sobre doenças raras apresenta intensificação a partir de 2013, com picos nos anos de 2015 (38 artigos), 2016 (44 artigos) e 2017 (41 artigos). É possível que esse fato se justifique por ter tal temática "um motor incentivador" que lhe deu visibilidade no meio científico a partir de 2014, no mundo, quando o parlamento e o conselho Europeu adotaram um novo programa de ação comunitária para a saúde pública ${ }^{13}$.

As doenças raras passaram, então, a ser prioridade no programa de saúde pública da União Europeia, sendo suas principais linhas de ação as trocas de informações através das redes de informação, e no desenvolvimento de estratégias e mecanismos de troca de informação e coordenação para incentivar a continuidade do trabalho e da cooperação transnacional.

O maior número de publicações a partir de 2015 pode também dever-se ao estímulo das legislações destinadas a tratamentos e incentivos às empresas farmacêuticas e de biotecnologia para desenvolver novos medicamentos, somado à atenção pelas pesquisas no âmbito da genética molecular, bioquímica e aos avanços tecnológicos ${ }^{6}$.

Ainda no período, constatamos que gradualmente a temática pela perspectiva qualitativa alcançou visibilidade em periódicos. A sensibilização da sociedade, pesquisadores e orgãos governamentais para as doenças raras aumentou nos últimos anos devido aos trabalhos das organizações associativas das pessoas e famílias com doenças raras na luta pelo reconhecimento do direito à vida e à saúde ${ }^{12}$.

Do ponto de vista histórico, em 1983, a criação da Organização Nacional de Desordens Raras (NORD), nos EUA, foi fundamental para a aprovação a Orphan Drug Act - Lei de incentivo ao Desenvolvimento de Drogas Orfãs - haja vista a negligência da indústria farmacêutica no desenvolvimento de tratamentos para as doenças raras $^{14}$. Em 1986, a Aliança Genética foi criada para aumentar a capacidade dos grupos de defesa genética, sendo que o primeiro levantamento sobre as dificuldades de pessoas com doenças raras foi realizado pela Comissão Nacional de Doença Órfã, pelo Governo dos EUA, em 1989.

Acrescido a isso, a inexistência de um reconhecimento universal de sistema de codificação tornou-se um obstáculo para o registro confiável de pacientes em bases de dados nacionais ou internacionais, prevenção da avaliação do impacto econômico e social oriundos de doenças raras ${ }^{15}$.

Com a crescente cautela das dificuldades associadas com as doenças raras e o valor de resolvê-las, tornou-se importante a colaboração internacional para localizar esses problemas e os seus tratamentos ${ }^{14}$. Assim, em 2005, na Suécia, realizou-se pela primeira vez a Conferência Internacional sobre Doenças Raras e Medicamentos Órfãos, cobrindo uma série de questões com o apoio do Escritório de Doenças Raras, Institutos Nacionais de Saúde dos EUA e as Comissões Europeias. Percebemos, assim, que houve inúmeras ações governamentais e institucionais nas décadas anteriores que incentivaram e/ou apoiaram o incremento da produção científica sobre doenças raras no interstício considerado.

Em relação ao país de origem, constatamos uma diversidade de distribuição geográfica das produções, evidenciando maior concentração de estudos nos Estados Unidos (50), seguido do Reino Unido (32), Canadá (15), Austrália (15) e Suécia (10), como mostra a Figura 2.

Assim como justificamos que o incremento da produção científica acerca das doenças raras guarda estreita relação com os acontecimentos históricos acima descritos, entendemos que tais acontecimentos também tenham influenciado o local de realização dessa produção, desenhando a distribuição geográfica por nós encontrada.

No que tange ao número pouco expressivo de produções brasileiras (6) no interstício temporal considerado, vale destacar que até o início dos anos 80 havia poucas iniciativas de enfrentamento das doenças raras como uma questão de Saúde Pública ${ }^{1}$. Apoiado na experiência americana para a elaboração de políticas locais, o Brasil, como forma de promover a coesão do grupo de pessoas com doenças raras, organizou em $2009^{15}$ o I Congresso Brasileiro de Doenças Raras, mesmo ano em que foi instituída a Política Nacional de Atenção Integral em Genética Clínica ${ }^{16}$. Em 2011, o manifesto público de diversas associações reunidas culminou, mais tarde, na criação da Políti- 
Figura 2. Distribuição espacial das produções (2019).

ca Nacional das Pessoas com Doenças Raras no SUS (PNAIPDR), instituída pela Portaria no 199 , de 30 de janeiro de $2014^{17,18}$.

Fonseca ${ }^{19}$ destaca que o cenário de construção dessa política brasileira foi marcado pela escassez de indicadores epidemiológicos nacionais sobre doenças raras que subsidiassem a determinação de sua situação real, bem como pela necessidade de que fossem estabelecidas ações e políticas destinadas à atenção às pessoas com doenças raras. Tais fenômenos podem explicar a ainda incipiente publicação científica brasileira, visto que o interesse nesse grupo de doenças foi reforçado após a promulgação dos referidos dispositivos legais.

Com relação às produções qualitativas no âmbito mundial, é notável sua presença no contexto europeu, já que por lá recai um elevado nível de proteção social em comparação a outras partes do mundo, o que inclui a atenção à maneira pela qual normas, processos sociais e costumes afetam a saúde. Nesse sentido, são importantes as ações coletivas que reivindicam que a questão das doenças raras seja promovida como prioridade de Saúde Pública, ou seja, assumida enquanto direito social e responsabilidade de Estado. Com esse intuito, destaca-se o papel de instituições como a European Organization for Rare Diseases (EURORDIS) que, desde a década de 1990, fomentada por organizações de pacientes e familiares, vem influenciando as políticas naquele contexto $^{20}$.
Do ponto de vista do diagnóstico, existem cerca de seis a sete mil doenças conhecidas, sendo que, semanalmente, a depender da especificadade das entidades/patologia, novas doenças são descritas na literatura médica ${ }^{13}$. Nos artigos selecionados, foi possível identificar 113 tipos de doenças raras como foco dos estudos, sendo as mais frequentes, por ordem do número de estudos em que aparecem, as seguintes: Distrofia Muscular de Duchenne (5), Fibrose Cística (3), Fibrose Pulmonar Idiopática (3), Esclerose Lateral Amiotrófica (3), Discinesia Ciliar Primária (3) e Osteogênese Imperfeita (3), Esclerodermia (2), Doença Falciforme (2), Mucopolissacaridose (2), Paralisia Supranuclear Progressiva (PSP) (2), Atrofia Muscular Espinhal (SMA) (2), Síndrome de Marfan (MFS) (2), Síndrome de Moebius (2), Epidermólise Bolhosa (EB) (2), Câncer de Mama em homens (2), Hipogonadismo Hipogonadotrófico Congênito (2) e Linfoma Cutâneo Primário de Células $\mathrm{T}$ (2). As 71 doenças raras restantes apareceram somente uma vez cada como foco de estudo. É importante ressaltar também que, em 58 textos, não foi especificada doença alvo.

Destacamos que o fato de haver pequeno número de estudos abordando uma determinada doença ou mesmo haver estudo único que a aborda não lhe diminui a importância, visto tratar tais estudos exatamente de doenças de ocorrência rara. Assim, a dispersão de um grande número dessas doenças pelos estudos capturados 
nos reforça as características de sua expressão na população em geral, tanto no que se refere a sua raridade, assim como ao aparecimento, ano a ano, de novas e, ainda, o conhecimento incipiente de suas manifestações confirmadas por estudos científicos.

Quanto ao idioma dos estudos publicados, apesar da diversidade de línguas oficiais dos diferentes países, predomina a publicação em inglês em 158 dos 171 textos, sendo os demais cinco em espanhol, quatro em português, dois em francês, um coreano e um em croata.

Com relação à área de conhecimento a que esses artigos se vinculam, foi possível identificar maior concentração em revistas da Medicina, com 64 (37\%) artigos, da Enfermagem, com 31 (18\%) produções, e da Saúde Pública, 12 (7,1\%), que será discorrida adiante.

\section{Estratégia de coleta de dados e temas abordados nas publicações}

Dentre as 171 publicações selecionadas, 90 $(52,63 \%)$ se utilizaram da entrevista como principal estratégia de coleta de dados. Em análise mais acurada, deparamo-nos com diversas especificações de tipos de entrevista, dentre as quais, destacou-se a semiestruturada, sendo mencionada em $44,44 \%$ (40) desses textos. As estratégias de grupo foram utilizadas em menor grau, correspondendo a $10,52 \%$ (18) do total de produções; e, dentre estas, a expressiva utilização da modalidade de Grupo Focal (GF), que correspondeu a $88,88 \%$ (16) dos textos.

No bojo das 63 produções restantes, encontramos $21(12,28 \%)$ estudos realizados por meio de métodos mistos, que propunham a realização de pesquisas de abordagem quantiqualitativa, utilizando técnicas que variavam entre questionários e observação participante, de modo a complementar os dados coletados. Localizamos, ainda, $17(9,94 \%)$ artigos de revisão de literatura, $13(7,60 \%)$ artigos reflexivos, $6(3,50 \%)$ artigos cuja coleta de dados se deu por meio de material online e $6(3,50 \%)$ estudos que não especificaram a estratégia de coleta utilizada. Na Figura 3, sintetizamos as estratégias de coleta de dados empregadas em cruzamento com a área de conhecimento do estudo.

Esses achados refletem algumas das inúmeras possibilidades de buscar a aproximação com a experiência do outro na abordagem qualitativa, ou seja, uma "intenção geral" de proximidade com o universo da subjetividade das pessoas. Nessa intenção, estratégias de coleta, tais como a entrevista ou as técnicas de grupo, tendem a ser priorizadas.

Concordamos que haja a pertinência dessas estratégias ao lidar com objetos de estudo que se constituam por meio de elementos subjetivos e interacionais, como é o caso das experiências de pessoas e famílias que convivem com algum adoecimento raro. Tais experiências desvelam, em si mesmas, tanto aspectos sociais como cognitivos, subjetivo-individuais como objetivo-coletivos ${ }^{21}$. Assim, há de se apreender tais especificidades a partir de elementos da vida cotidiana e suas relações, ainda que em perspectiva.

Quanto às revisões de literatura, são, especialmente, importantes no sentido de situar determinado tema dentro de um contexto de publicações que oferecem um panorama do estado da arte do conhecimento científico em relação ao que se pretende explorar. Vale salientar que não encontramos nenhuma revisão de literatura no contexto brasileiro, o que reforça a relevância e o ineditismo do presente estudo, já que, segundo autores $^{22}$, a revisão de literatura também auxilia o pesquisador na captação de fontes de ideias para novas investigações contextualizando o que já é conhecido com a percepção de temas/problemas ainda pouco pesquisados.

Quanto à área de conhecimento da publicação, destacam-se: a Medicina, com 64 (37\%) artigos; a Enfermagem, com 31 (18\%) produções; e a Saúde Pública, 12 (7,1\%). Embora sejam estas componentes, majoritariamente, da área da saúde, há também de se considerar a especificidade da base de dados para predileção das publicações. Em "Outras áreas" foram englobadas as publicações unitárias da Filosofia, Antropologia, Odontologia, Música, Biomedicina e Empreendedorismo.

A coleta de dados por meio de entrevista semiestruturada se sobressai como a principal estratégia utilizada pela Medicina e Enfermagem. Nestas, a entrevista é utilizada majoritariamente, consituindo-se $37(57,81 \%)$ e $19(61,29 \%)$ do total de produções nessas áreas, respectivamente, demonstrando certa "concentração" (ou predileção) por esse tipo de acesso às informações das pessoas. A Psicologia também emprega a entrevista em número expressivo do total de seus estudos (50\%).

Para a área da saúde pública, a entrevista e o grupo focal, em conjunto, mostram certa expressividade, $5(31,25 \%)$, mas não são de maior relevância, diluindo-se na variedade de estratégia de coleta de dados apresentada em seus estudos. Cabendo destaque aos estudos de Revisão de Li- 


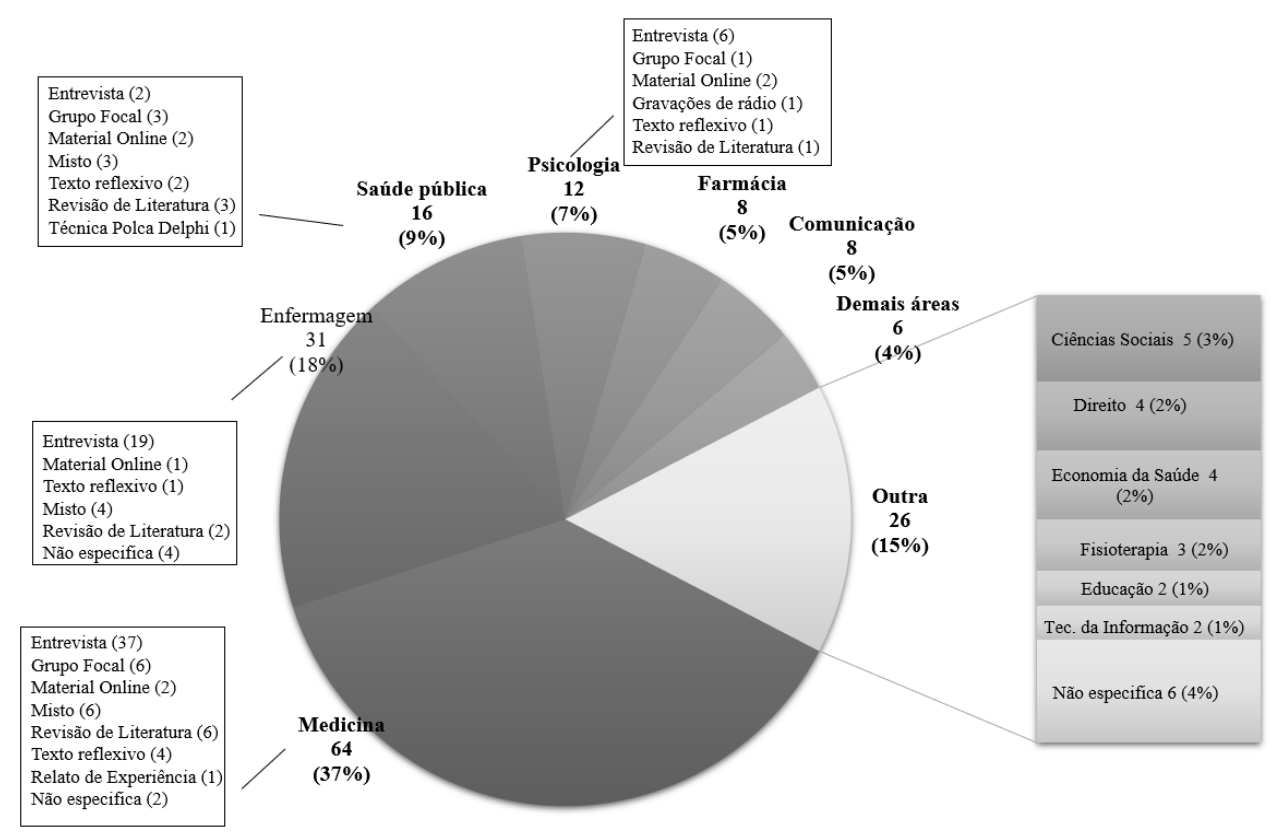

Figura 3. Distribuição da publicação por área de conhecimento e por estratégia de coleta de dados (2019).

teratura que representam $3(18,75 \%)$ do total de estudos nessa área.

Em relação aos estudos de revisões de literatura, a área da Medicina foi a que mais produziu esse tipo de estudo em termos absolutos, com 6 publicações no período estudado. Entretanto, esse número representa apenas $9,37 \%$ do total de produções da área; em seguida, temos a Enfermagem com 2 estudos, que respresentam 10,52\% da publicação na área, e Psicologia com 1 estudo, representando 8,3\% do total de produções nessa área.

No que tange aos temas abordados, verificamos multiplicidades de enfoques e categorizamos os textos de acordo com aspectos que se correlacionavam, resultando em 11 temas. Os temas mais expressivos, quantitativamente, foram: 1 . Experiências de pessoas e famílias que convivem com algum adoecimento raro, com 106 (61,98\%) textos; 2. ferramentas de compartilhamento de informações online e criação de instrumentos que oferecem dados sobre doenças raras, com 22 $(12,86 \%)$ textos; e 3. Perspectivas de profissionais que atuam no serviço perante o amparo de pessoas adoecidas, quantificando $10(5,84 \%)$ textos.

Em relação ao tema 1, observamos que a experiência de pessoas e famílias que convivem com adoecimento raro é trazida nas publicações dentro de uma divesidade de contextos, quais sejam: na casa, no trabalho, na comunidade e também no hospital. Nesse sentido, a experiência em condições de cronicidade alcança o cotidiano, de modo que esse achado reflete um movimento de ampliação do olhar para além dos muros hospitalares, entendendo a saúde dentro de uma perspectiva que abarca a vida em suas diversas dimensões e lugares de acontecer. Em relação aos participantes da pesquisa que relataram aspectos da conviência com um adoecimentos raro postos pela experiência que abarca diferentes esferas da existência, constatou-se predomínio da perspectiva das mães, seguidas dos pais, diversos entes familiares implicados no cuidado e da própria pessoa adoecida.

Dentre os aspectos da experiência das pessoas e famílias abordados nos estudos, ganharam relevo o impacto de receber o diagnóstico de um adoecimento raro, a necessidade de cuidado que os adoecidos demandam, o aprender a lidar com a situação que se instaura - muitas vezes permeada por estigmas e preconceitos de diversas ordens, os sentimentos e emoções envolvidos em todo processo do viver e cuidar, a espiritualidade como instrumento para lidar com a situação.

Em relação ao tema 2 - Ferramentas de compartilhamento de informações online e criação de instrumentos que oferecem dados sobre doenças raras - reunimos publicações que trabalharam com informações compartilhadas em blogs, 
redes sociais e outras mídias, demonstrando que essas ferramentas podem auxiliar pessoas e famílias que convivem com o adoecimento raro. Inclusive, um $(4,54 \%)$ dos textos abordou o uso de aplicativos móveis para relatar reações adversas a medicamentos e outras informações de segurança ao paciente. Houve destaque também para a importância da criação de websites que reúnam informações sobre a localização de recursos que possam auxiliar pessoas e famílias no engendramento do cuidado.

Dois $(9,9 \%)$ textos também trouxeram a intervenção telefônica realizada por profissionais de saúde no sentido de auxiliar, com maior agilidade, pessoas com doenças raras.

No tópico 3, as produções abordaram a perspectiva profissional no tocante ao tratamento, diagnóstico e condutas adequadas ao quadro apresentado pelos pacientes em questão. Os estudos aqui reunidos apresentam um olhar mergulhado no conhecimento biomédico que se preocupa com caracterísiticas específicas de determinada doença rara, bem como acerca da alocação de recursos em saúde nesse âmbito.

Dada a importância do olhar biomédico na busca por compreender as doenças raras e suas caracteríticas ainda pouco exploradas e apreendidas pelos profissionais de saúde, acreditamos que os aspectos aqui apontados são essenciais para que, em conjunto, possam compor um mosaico de compreensão do que seja viver e cuidar na ocorrência da doença rara.

Os demais temas, que contabilizaram 33 textos, ou seja, 19,29\% do total, embora em menor quantidade separadamente, revelam a preocupação em tornar visíveis as necessidades sociais e individuais que perpassam o viver com doença genética rara. Ganharam destaque discussões sobre o diagnóstico, medicamentos órfãos, grupos de apoio social e da comunidade diante das necessidades em saúde, judicialização em saúde, políticas públicas, qualidade de vida, definição de doença rara e tratamento.

Tais temáticas aqui encontradas retratam a relevância e o investimento em discussões cada vez mais próximas dos contextos sociais oriundos de ações cotidianas da experiência da doença e evidenciá-las, por sua vez, pode subsidiar novas pesquisas qualitativas sobre doença genética rara, principalmente no contexto brasileiro, de forma a potencializar e auxiliar pesquisadores/estudos que tenham interesse na temática.

\section{Conclusões}

Ao darmos visibilidade às tendências das produções nos últimos cinco anos, observamos que a experiência da doença rara vem sendo abordada nas áreas estudadas sob diversos prismas, evidenciando a necessidade de que os estudos qualitativos continuem a caminhar no sentido de conferir relevo às diversas subjetividades envolvidas no processo de adoecer e cuidar, de modo a ultrapassar o enfoque exclusivo dos sinais e sintomas específicos de determinada doença genética rara. Além do mais, os trabalhos localizados revelam a pertinência e o potencial dos estudos de cunho qualitativo, ao cobrirem variadas estratégias metodológicas e temáticas no bojo do tema geral das doenças genéticas raras, o que pode subsidiar a organização, a tomada de decisões e a formação em saúde que visa atender às necessidades das pessoas adoecidas e suas famílias.

Ainda, ao emergirem reflexões da luta pelo direito à saude, a proposta de uma política integral voltada às pessoas com doenças raras de forma genérica (com dois eixos, sendo o I composto pelas doenças genéticas que incluem as anomalias congênitas ou de manifestação tardia, deficiência intelectual, erros inatos de metabolismo; e o II pelas doenças não genéticas, a saber, as infecciosas, inflamatórias e autoimunes) constituiu importante conquista de grupos sociais organizados que tiveram a potência de fazer com que o Estado viesse a incorporar essa proposta refletindo, sobretudo, na produção brasileira em relação ao tema. Vale lembrar que, como desdobramento dessa política, a partir de 2016, o Ministério da Saúde habilitou estabelecimentos de saúde para funcionarem como Serviços de Referência para Doenças Raras integrados ao Sistema Único de Saúde, sendo que, até fevereiro de 2019, eram oito (localizados em Anápolis/GO, Distrito Federal, Recife/PE, Curitiba/PR, Rio de Janeiro/RJ, Porto Alegre/RS, Santo André/SP e Salvador/BA) ${ }^{23}$. Os hospitais de ensino/universitários também são alternativa para atendimento (e pesquisa), assim como outras unidades integradas à rede pública de saúde. Contudo, há de considerar que a política em questão é relativamente nova e está em curso; que sua implementação como as políticas dirigidas às condições complexas (como é o caso das raras), geralmente, não ocorrem uniformente nas diferentes regiões e estados brasileiros; e, por fim, que, estando significativamente no âmbito dos serviços públicos de saúde, pode refletir a atual conjuntura da política nacional com 
os retrocessos na área social o que, mais ainda, justifica o fortalecimento da mobilização coletiva em defesa da saúde como direito constitucional.

Para finalizar, torna-se importante ressaltar que as produções aqui selecionadas não se referem à totalidade de estudos realizados no contexto brasileiro e mundial, uma vez que muitos trabalhos, como teses, dissertações, livros, textos completos de anais de congresso e que não estavam indexados, não compuseram o levantamento e podem não ter sidos publicados nas bases de dados consultadas.

Consideramos que este estudo preenche, em certa medida, uma lacuna no cenário de produ- ções brasileiras e mundiais no sentido de oferecer um mapeamento de como a doença rara vem sendo abordada pelas pesquisas de cunho qualitativo, apontando para a necessidade do desenvolvimento de novos estudos que revelem outras faces da experiência de cuidado em relação a pessoas adoecidas. Também nos parece importante examinar as potencialidades que a produção do conhecimento qualitativo têm para responder, singularmente, as muitas e variadas necessidades das pessoas e famílias, embasando melhores práticas profissionais, bem como ações políticas e governamentais que lhes ofereçam apoio ao viver e ao cuidar na doença rara.

\section{Colaboradores}

IP Souza e JS Androlage trabalharam na concepção, análise e interpretação dos dados, redação do artigo, revisão crítica, bem como na aprovação da versão a ser publicada. R Bellato trabalhou na análise, interpretação dos dados, redação do artigo e revisão crítica, bem como na aprovação da versão a ser publicada. RA Barsaglini trabalhou na concepção, interpretação dos dados, revisão crítica, bem como na aprovação da versão a ser publicada. 


\section{Referências}

1. Associação da Indústria Farmacêutica de Pesquisa (Interfarma). Doenças Raras: A urgência do acesso à saúde. São Paulo: Interfarma; 2018.

2. Brasil. Ministério da Saúde (MS). Doenças raras: o que são, causas, tratamento, diagnóstico e prevenção. 2019 [acessado 2019 Fev 19]. Disponível em: http://portalms.saude.gov.br/saude-de-a-z/doencas-raras

3. Rare Diseases Europe (Eurordis). What is a rare disease?; 2018 [acessado 2019 Mar 19]. Disponível em: https://www.eurordis.org/content/what-rare-disease

4. Picci RLL, Oliva F, Trivelli F, Carezana C, Zuffranieri M, Ostacoli L, Furlan PM, Lala R. Emotional Burden and Coping Strategies of Parents of Children with Rare Diseases. J Child Fam Stud 2015; 24(2):514-522.

5. Aureliano WA. Trajetórias Terapêuticas Familiares: doenças raras hereditárias como sofrimento de longa duração. Cien Saude Colet 2018; 23(2):369-379.

6. Richter T, Nestler-Parr S, Babela R, Khan ZM, Tesoro T, Molsen E, Hughes DA. Rare Disease Terminology and Definitions - A Systematic Global Review: Report of the ISPOR Rare Disease Special Interest Group. Value Health 2015; 18(6):906-914.

7. Minayo MCS. O desafio do conhecimento: pesquisa qualitativa em saúde. 14a ed. São Paulo: Hucitec; 2014.

8. Souza CD, Filippo D, Casado ES. Crescimento da atividade científica nas universidades federais brasileiras: análise por áreas temáticas. Avaliação, Campinas 2018; 23(1):126-156.

9. Bosi MLM. Pesquisa qualitativa em saúde coletiva: panorama e desafios. Cien Saude Colet 2012; 17(3):575-586.

10. Whittemore R, Knafl K. The integrative review: updated methodology. J Adv Nurs 2005; 52(5):546-553.

11. Falagas ME, Pitsouni EL, Malietzis GA, Pappas G. Comparison of PubMed, Scopus, Web of Science, and Google Scholar: strengths and weaknesses. FASEB J 2008; 22(2):338-342.

12. Moreira MCN, Nascimento MAF, Horovitz DDG, Martins AJ, Pinto M. Quando ser raro se torna um valor: o ativismo político por direitos das pessoas com doenças raras no Sistema Único de Saúde. Cad Saude Publica 2018; 34(1):e00058017.

13. Orphanet [Internet]. Sobre doenças raras; 2012 [acessado 2019 Mar 19]. Disponível em: https://www. orpha.net/consor/cgibin/Education_AboutRareDiseases.php?lng=PT\&stapage=ST_EDUCATION_EDUCATION_ABOUTRAREDISEASES\#AboutRD

14. Schieppati A, Henter J-I, Daina E, Aperia A. Why rare diseases are an important medical and social issue. Lancet 2008; 371(9629):2039-2041.
15. Oliveira CRO, Guimarães MCS, Machado R. Doenças raras como categoria de classificação emergente: o caso brasileiro. Data Grama Zero 2012; 13(1):1-10.

16. Brasil. Portaria no 81 , de 20 de Janeiro de 2009. Institui, no âmbito do Sistema Único de Saúde (SUS), a Política Nacional de Atenção Integral em Genética Clínica. Diário Oficial da União 2009; 21 jan.

17. Brasil. Portaria $n^{\circ} 199$, de 30 de Janeiro de 2014. Institui a Política Nacional de Atenção Integral às Pessoas com Doenças Raras com Diretrizes para Atenção Integral às Pessoas com Doenças Raras no âmbito do Sistema Único de Saúde (SUS) e institui incentivos financeiros de custeio. Diário Oficial da União 2014; 31 jan.

18. Lima MAFD, Gilbert ACB, Horovitz DDG. Redes de tratamento e as associações de pacientes com doenças raras. Cien Saude Colet 2018; 23(10):3247-3256.

19. Fonseca RVG. A construção de uma política pública para doenças raras no Brasil [monografia]. Brasília: Universidade de Brasília; 2014.

20. Barbosa RL. Ninguém nasce doente, torna-se doente! Itinerários de diagnóstico e Itinerários terapêuticos no caso da Neurofibromatose [tese]. Coimbra: Universidade de Coimbra; 2017.

21. Alves PC. Experiencing Illness: Theoretical Considerations. Cad Saude Publica 1993; 9(3):263-271.

22. Sousa LMM, Firmino CF Marques-Vieira CMA, Severino S, Pestana HCFC. Revisões da literatura científica: tipos, métodos e aplicações em enfermagem. Rev Port Enferm Reabil 2018; 0:46-55.

23. Brasil. SUS oferece tratamento para doenças raras; saiba como procurar ajuda. Publicado em Notícias. Atendimento. 28/02/2019. [acessado 2019 Jun 5]. Disponível em: http://www.brasil.gov.br/noticias/ saude/2019/02/sus-oferece-tratamento-para-doencas-raras-saiba-como-procurar-ajuda

Artigo apresenado em 29/04/2019

Aprovado em 01/07/2019

Versão final apresentada em 03/07/2019 